\section{ASsurance of integrated reports: the state of the art}

Professor Mădălina DUMITRU, Phd. Bucharest University of Economic Studies, e-mail: Madalina.Dumitru@cig.ase.ro

Associate Professor Raluca Gina GUŞE, Phd. Bucharest University of Economic Studies, e-mail: GGuse@cig.ase.ro

\section{Albstract}

The focus of this paper is the issue of assurance of different sustainability, social, environmental or governance sections of companies' annual reports, which fall under the umbrella of integrated reports. The main research questions are: which are the sections assured; to what extent are the accounting and audit professionals involved in the assurance process of integrated reports; and which are the standards used in the assurance missions. We explore the integrated reports issued in 2014 by 98 companies included in the International Integrated Reporting Council's Pilot Programme. Our main conclusions are that most of the companies obtain assurance only for a part of the information disclosed in the integrated reports, most of the reports are assured by the accountancy companies and the most used standard is ISAE 3000. The article is important for the accounting practitioners as it presents new opportunities for the development of the profession. From the academic point of view, the discrepancy between our results and the results of the studies based on sustainability reports proves that the assurance of the integrated reports is a specific theme, which should be studied separately.

Keywords: assurance, accounting professionals, integrated reporting, Pilot Programme, assurance standards

JEL Classification: M14, Q56 


\section{Introduction}

An increasing number of companies embedded corporate social responsibility information, social, environmental, sustainability information and other types of non-financial information into their annual reports or issued similar stand-alone reports. The new types of reports are generically named "integrated reports." Assurance mechanisms and other instruments are necessary in order to ensure the credibility and trust of corporate reports, especially as the International $<$ Integrated Reporting> Framework (IIRF) recognizes the investors as the primary audience of the integrated reports.

So far, for the assurance of integrated reports disclosure committees and internal audit assignments, advisory services provided by external consultants, independent assurance engagements by practitioners on the information and the related systems and processes were used (IAASB, 2015a).

The need to improve the credibility and trust was signalled by the International Integrated Reporting Council (IIRC) and the International Auditing and Assurance Standards Board (IAASB) in the issued papers and by forming working groups (for instance, IAASB's Integrated Reporting Working Group was established in September 2014). The role of independent external assurance on integrated reports leading to their enhanced reliability, as well as the difficult nature of appropriate standards was also signalled by Oprişor (2015). At the same time, there are an increasing number of companies which obtain assurance for their integrated reports.

The assurance of integrated reports generates the need for assurance standards, which is to be addressed by the standard setters. Additionally, the practitioners need to build the necessary skills in order to provide a professional opinion concerning this new form of corporate reports. In this paper, we focus on the current state of assurance practice associated with integrated reporting and also on the involvement of accounting and auditing professionals in the assurance missions. The importance of this issue was recognized by the IIRC (2015) and Eccles, Krzus and Watson (2012). We aim to explore the role that competent accounting and auditing professionals have in preparing and providing assurance on the new forms of corporate reports. Another research question addressed by our paper is which are the standards used for the assurance of this type of reports.

There are no papers published in this area so far (IAASB, 2015b), and this is why in our literature review section we will consider the papers approaching similar issues, such as the competencies of the accounting professionals which assure sustainability reports or GHG emissions statements. By this research we fill a gap in the accounting literature and we answer the call of the IAASB for academic research in the field.

We decided to study the assurance of integrated reports, as opposed to the assurance on non-financial information, because we expected to obtain a more comprehensive picture. Getting involved now, when the integrated reporting is still at the beginning of its journey, is important in order to support building a robust assurance process. Assurance is already being provided on some integrated reports and there is a risk that these assurance engagements may be to the detriment of what is in the public interest in the absence of an appropriate assurance standard for these engagements (Ms. Diplock, IAASB, 2015c).

This type of research is important for the accounting and auditing professionals as they have to seize the momentum and try to secure a market share as big as possible in this new activity.

The paper is structured as follows. The next section discusses the state of the art in the field of assurance of the integrated reports. The third section presents the research methodology used in the paper. The research results are presented in the fourth section, and the paper ends with our conclusions.

\section{The state of the art in the area of the assurance of the integrated reports}

The IIRF is not asking specifically for the integrated reports to be assured. Yet, recent studies from the Big Four companies (such as KPMG, 2013 and 2015 or Deloitte, 2014) report that an increasing number of companies prepare integrated reports and that there is an increasing interest of other companies/managers to switch to this type of reporting. Credibility is one way to increase the interest in non-financial information (Eccles, Krzus and Watson, 2012). As there is a strong demand 
for integrated reporting, we consider that in the near future there will be a need for assurance on this type of reports. Deloitte (2014), for instance, reports that $55 \%$ of the 250 companies included in the sample selected for their study obtain assurance of their sustainability reports, up from $28 \%$ in 2012.

The International Standard on Auditing (ISA) 720 "The Auditor's Responsibilities Relating to Other Information" revised has strengthened the auditor's responsibilities in connection with "other information." "Other information" is defined as "financial and non-financial information (other than the financial statements and the auditor's report thereon) included in an entity's annual report" (IAASB, 2015a). This fact supports our opinion that special attention should be given to the conditions in which the assurance engagements for the integrated reports are conducted. The professionals involved in the assurance engagements might rely on the work of internal auditors, ESG auditors etc.

In relation to the integrated reports, the current practice used by companies is to obtain an audit opinion for the financial statements section of the reports and a separate opinion for a selection of non-financial information. This combination, however, does not provide an "integrated" audit opinion.

Assurance is a process undertaken by a competent and independent external practitioner, to acquire sufficient appropriate evidence and express a written conclusion that enhances the degree of confidence intended users can place in the organization's integrated report (IIRC, 2014). In simpler terms, assurance with respect to integrated reporting $(<|R\rangle)$ is typically considered to be an independent conclusion on whether an organization's integrated report presents its strategy, governance, performance and prospects in accordance with the IIRF (IIRC, 2014). Assurance with regard to integrated reporting may also be obtained on different subjects, such as the process of preparing an integrated report or the information included in the report. However, according to IAASB (2015), it is preferable that all the principles included in the IIRF be assured.

One of the unsolved issues in relation with the assurance of the integrated reports refers to the capabilities of the persons who are to take part in an assurance engagement for integrated reporting. KPMG (2008) and Simnett, Vanstraelen and Chua (2009) find that $65 \%$ and, respectively, $43 \%$ of the assured reports included in their samples were assured by accountants.
Professional accountants can add value to assurance engagements with regard to integrated reporting, having knowledge of corporate reporting in general, of reporting processes, internal control and experience in performing assurance engagements. Yet, performing an assurance engagement with regard to integrated reporting may require specialized skills and knowledge (IAASB, 2015d). Thus, it may be necessary to involve a team made up by practitioners in different fields for such an engagement. However, having certified auditors as members of an assurance team brings several advantages stemming from their experience in risk assessment, occurrence and accuracy assertions, structuring of the assurance/audit report, as well as their acquired abilities such as teamwork (in multidisciplinary teams), relevant education and continuing professional development, or the compliance with the Code of Ethics, policies and procedures issued by a professional association such as the IAASB (Huggins, Green and Simnett, 2011). Yet, the multidisciplinary teams may be difficult to manage.

Another problem raised by the assurance of the integrated reports is related with the standards which should be used by the practitioners. In general, the professionals choose between two standards: International Standard of Assurance Engagements (ISAE 3000, Revised), "Assurance Engagements Other than Audits or Reviews of Historical Financial Information", issued by the IAASB and AA1000 "Assurance Standard" issued by Accountability. The assurance report prepared using AA1000AS highlights the strengths and weaknesses of report content, as well as the organization's underlying management systems and its responsiveness to stakeholder concerns (Lungu et al., 2010). An assurance opinion prepared using ISAE 3000 emphasizes the limitations and weaknesses of the company's reporting process. Sustainability Accounting Standards Board (SASB) encourages the use of AT Section 101 of the American Institute of Certified Public Accountants' Statements on Standards for Attestation Engagements.

An issue which should be taken into consideration by the professionals which are conducting the assurance mission refers to the criteria used by the company which prepared the integrated report. This can be formal (when required by law, for instance) or less formal. The benchmarks in this domain are the guidelines released by the Global Reporting Initiative (IAASB, 2015d). 


\section{Research methodology}

Our research is based on the content analysis of the annual reports published in 2014 by the organisations included in the IIRC's Pilot Programme. 98 organisations were identified which correspond to this criterion. The annual reports analysed were the ones published by the entities on their websites.

We extracted from the annual reports general data regarding the organisation (continent, activity domain, the size of the annual report expressed in the number of pages) and data about the content of the report, focusing on the aspects related with the assurance of the sections in the annual report which are generally associated with the non-financial information presented in the integrated reports, such as sustainability, social and environmental aspects or governance. More exactly, we extracted by hand the following information regarding the assurance report:

- The existence of the information regarding the assurance of the sections associated with the nonfinancial reporting;
- Information regarding the use of the guidelines issued by the Global Reporting Initiative as a reporting criteria;

- The assured sections of the integrated report;

- The type of assurance missions: the assurance of the entire report or the partial assurance;

- The auditor type by activity domain: accountancy or others;

- The standards used within the assurance missions: ISAE 3000, AA1000AS, other standards;

- The inclusion of the assurance opinion in the integrated report;

- The number of pages of the assurance report included in the integrated report;

- Examples of information which are not assured;

- The presentation of supplementary information regarding the assurance mission associated with the integrated reporting on the company's website.

The way in which the variables used in this research were codified is presented in Table 1.

Table 1. The codification of the variables used in the research

\begin{tabular}{|c|c|c|}
\hline No. & Description & Code \\
\hline 1 & The continent on which the company is established & $\begin{array}{l}\text { 1- Europe } \\
2 \text { - America } \\
3 \text { - Africa } \\
4 \text { - Asia and Australia }\end{array}$ \\
\hline 2 & The main activity domain of the company & $\begin{array}{l}1 \text { - Manufacturing } \\
2 \text { - Others }\end{array}$ \\
\hline 3 & The total number of pages of the integrated report & - \\
\hline 4 & The type of the assurance mission & $\begin{array}{l}0 \text { - Is not presented } \\
1 \text { - Complete } \\
2 \text { - Partial }\end{array}$ \\
\hline 5 & The domain of the auditor which assured the integrated report & $\begin{array}{l}0 \text { - Is not presented } \\
1 \text { - Accounting } \\
2 \text { - Others }\end{array}$ \\
\hline 6 & The standard based on which the assurance was conducted & $\begin{array}{l}0 \text { - Is not presented } \\
1 \text { - ISAE } 3000 \\
2 \text { - AA } 1000 A S \\
3 \text { - Others } \\
4 \text { - ISAC } 3000 \text { and AA1000AS }\end{array}$ \\
\hline 7 & Is the assurance included in the integrated report? & $\begin{array}{l}0-\text { No } \\
1-\text { Yes }\end{array}$ \\
\hline 8 & $\begin{array}{l}\text { The criteria used for the measurement and presentation of the non-financial information } \\
\text { in the integrated report }\end{array}$ & $\begin{array}{l}1-\mathrm{GRI} \\
0-\text { Others }\end{array}$ \\
\hline 9 & The total number of pages of the assurance report & - \\
\hline
\end{tabular}

Source: authors' compilation 
The hypotheses of our research were the following:

1. Most of the assurance missions conducted on the integrated reports have a partial character;

2. Most of the companies which assure the nonfinancial information included in the integrated reports work with accountancy entities;

3. Most of the companies which offer assurance services for the non-financial information included in the integrated reports use ISAE 3000 as a basis for the formulation of the assurance opinion.

\section{Research resulits}

Out of the 98 companies analysed 52 are from Europe, 23 from America, 6 from Africa and 17 from Asia and Australia. 43 companies have manufacturing as a main activity domain, the others having different activity domains.

29 companies out of the 98 include in the assurance report in the integrated report. For other 6 companies we found references in the integrated reports that they published the assurance opinion on their website. This means that $35.71 \%$ of the companies analysed disclose the assurance report. This percentage is a lot smaller than the one reported by Deloitte (2004) regarding the sustainability reports (62\% in 2013). A few of the explanations may be:

- The integrated reports have to be concise and, thus, they do not include the assurance report;

- The companies assure separately the sustainability reports but they do not assure the non-financial component in the integrated reports as well;

- The assurance opinion for the next year was already posted online and the link in the integrated report is no longer active or the internet search engines are directing us to the most recent assurance report.

The situation regarding the companies which present the assurance reports by continents is presented in Table 2 .

\begin{tabular}{|c|c|c|}
\hline No. & Continent & Percentage \\
\hline 1 & Europe & $33.33 \%$ \\
\hline 2 & America & $31.81 \%$ \\
\hline 3 & Africa & $33.33 \%$ \\
\hline 4 & Asia and Australia & $41.18 \%$ \\
\hline
\end{tabular}

Source: authors' compilation

If in the first three cases the percentages are close to each other and slightly below average, we notice that in Asia and Australia the percentage of the companies which obtain assurance for the annual report is much higher.

$40 \%$ of the companies which activate in manufacturing obtain an assurance report, while $30 \%$ of the companies which have a different main activity domain disclose the assurance report.

\section{Hypothesis 1. Most of the assurance missions conducted on the integrated reports have a partial character}

Analysing to what degree the integrated reports benefit from assurance, we noticed that $60.20 \%$ of the companies do not present if they obtained assurance for the entire report or just for some sections of the report. Out of the companies which present this aspect, in $72 \%$ of the cases the assurance is partial, while $28 \%$ of the companies assure the entire report. In other words, only in the case of $11.14 \%$ of the companies analysed we can say for certain that the integrated report benefits from assurance for the entire report. Our research hypothesis is confirmed.

Regarding the partial or complete assurance of the information in the integrated report we present the following information:

\section{Table 3. Types of assurance of the information included in the integrated reports}

\begin{tabular}{|l|r|r|c|}
\hline \multicolumn{1}{|c|}{ Items } & Number of reports & $\begin{array}{c}\text { Of which, assured by } \\
\text { a Big Four company }\end{array}$ & $\%$ \\
\hline Integrated reports for which assurance was obtained (total or partial) & 39 & 27 & 69.23 \\
\hline Integrated reports for which assurance was obtained (total) & 11 & 4 & 36.36 \\
\hline Integrated reports for which assurance was obtained (partial) & 28 & 23 & 82.14 \\
\hline
\end{tabular}

Source: authors' compilation 
We noticed that $54.54 \%$ of the opinions issued for the entire report were given by entities in other domains than accountancy. We noticed that a small number of entities benefitted from assurance services for the entire integrated reports and, out of them, less than a half worked with a Big Four company. The small number of integrated reports assured in full by the accountancy companies proves the difficulty of assuring the information included in the integrated reports in general and by the accounting professionals in particular. We can name at least two reasons for this state of facts:

- The high volume of data: this leads to the necessity to standardize the reporting practices; and

- The nature of the information presented: the use of multidisciplinary teams is needed and they are difficult to manage.

The results obtained in our study are significantly different from the results of the KPMG study regarding the sustainability reports. In their case, about $50 \%$ of the assurance opinions were granted for the entire report (KPMG, 2015).

After analysing the content of the assurance reports we noticed that the providers of the assurance services mentioned the following sections which were not assured: the prospective information, the objectives and expectations of the companies, the capital, the solvency, the market value of the new products, the details regarding the board, the customers, the suppliers, the financial information etc. On the opposite end, most of the reports mentioned the assurance of the key performance indicators, the information regarding the sustainability, the principles included in the reporting frameworks.

\section{Hypothesis 2. Most of the companies which assure the non-financial information included in the integrated reports work with accountancy entities}

A number of 56 of the analysed companies (representing 57.14\%) don't present the name of the company which assured the integrated report. Out of the other 42 entities, 31 (74\%) contracts assurance services from accountancy companies and $11(26 \%)$ from companies in other domains. Also, out of the 31 companies which work with accountancy entities, 30 chose a Big Four company (representing $71.43 \%$ out of 42 entities). Seven companies disclose the name of the assurer, but they do not disclose the content of the report. A cause could be the resource availability and the fact that Big Four companies had the necessary resources (material, but especially human) to answer the demand of assurance in the field of integrated reporting. Our research hypothesis was confirmed.

This result is convergent with the ones of the KPMG study (2015). According to that the big accountancy companies assure $64 \%$ of the sustainability reports of the biggest 100 companies in the analysed countries (N100) and $65 \%$ of the sustainability reports of the first 250 Global Fortune companies (G250).

\section{Hypothesis 3. Most of the companies which offer assurance services for the non-financial information included in the integrated reports use ISAE 3000 as a basis for the formulation of the assurance opinion}

According to the data extracted, 60 companies out of 98 (representing 61.22\%) do not disclose the standards on which the assurance opinion was formulated.

Statistically, the data is summarized in Table 4.

\begin{tabular}{|c|c|c|c|}
\hline Standards used & Total & $\begin{array}{l}\text { Accountancy } \\
\text { companies }\end{array}$ & $\begin{array}{c}\text { Other } \\
\text { domains } \\
\text { companies }\end{array}$ \\
\hline ISAE 3000 & $37 \%$ & $35.48 \%$ & $27.27 \%$ \\
\hline AA1000AS & $21 \%$ & $6.46 \%$ & $45.45 \%$ \\
\hline Other standards & $37 \%$ & $38.71 \%$ & $18.18 \%$ \\
\hline $\begin{array}{l}\text { ISAE } 3000 \text { and } \\
\text { AA1000AS }\end{array}$ & $5 \%$ & $6.46 \%$ & \\
\hline Total & $100 \%$ & $87.11 \%$ & $90.90 \%$ \\
\hline
\end{tabular}

Source: authors' compilation

For $37 \%$ of the assurance missions ISAE 3000 was used, for $21 \%$ AA $1000 \mathrm{AS}$, for $37 \%$ other standards and for $5 \%$ both ISAE 3000 and AA1000AS were used. A number of 11 accountancy companies used ISAE 3000 and 2 used both ISAE 3000 and AA1000AS $(41.94 \%$ in total). In four reports the standard used was not presented. As a result of our data analysis we noticed a fundamentally different situation in terms of the standards used by the non-accountancy entities. Therefore, $45.45 \%$ of these entities use the AA $1000 \mathrm{AS}$ standard, $27.27 \%$ use the ISAE 3000 standard, $18.18 \%$ use other standards and one other entity does not specify the employed standard. Also, most entities are certified by the Accountability organization. 
Our result is correlated with that reported by the IFAC (2008) in relation to the assurance for greenhouse gas emissions. Our research hypothesis was confirmed.

\section{Other research results}

We were able to survey a number of 35 assurance reports issued for the companies in our sample. In 68.18 of these reports there was mentioned the use of the Global Reporting Initiative standards as a reporting criteria. This result is correlated with those of the KPMG study (2015).

By analysing the size of the assurance reports, we noticed that usually, these are concise. Even if conciseness is a general characteristic of auditors' opinion expressed by the means of audit reports, we believe that in the case of non-financial information, a more developed version of the assurance report can contribute to the enhancement of report reliability, especially in the absence of mandatory reporting standards. The information regarding the number of pages of the assurance reports are summarized in Table 5.

\begin{tabular}{|l|r|}
\hline $\begin{array}{l}\text { Table 5. Number of pages of the assurance } \\
\text { reports }\end{array}$ \\
\hline \multicolumn{1}{|c|}{ Items } & Value \\
\hline Average number of pages & 2.36 \\
\hline Standard deviation & 1.38 \\
\hline Minimum number of pages & 1 \\
\hline Maximum number of pages & 8 \\
\hline
\end{tabular}

Source: authors' compilation

The reports issued by professionals in fields other than accountancy tend to be longer. In these cases, the average number of pages is 2.45 per assurance report, while in the case of reports issued by the accounting professionals the average size of the report is 1.65 pages.

\section{Conclusions}

As the practice of integrated reporting is evolving at the same time related standards are perfected, the assurance of integrated reports must evolve as well. Our research identifies several aspects that must be resolved in the near future in order to ensure the credibility and trust of integrated reports by means of the assurance processes, which can be perceived as opportunities for the development of the profession.

One of the questions that arise as a result of the new reporting practices is if the assurance processes should cover specific sections of the integrated reports or the reports as a whole. As previously expressed in the literature, the current dominant practice of targeting specific sections of integrated reports can only lead to a limited degree of assurance. However, the assurance of the integrated reports in their entirety requires a new set of professional standards and competencies.

The need for professional standards in the field is also supported by our findings related to the actual standards used by the assurers. Even if the ISAE 3000 standard is used by a large number of assurance services providers in the accountancy firms, the other assurers display a preference for the AA1000AS standard. Even so, neither the ISAE 3000 nor the AA1000AS is used by more than $45 \%$ of assurers. Therefore, no one standard has yet been accepted as a reference by all (or the majority of) assurers.

Another problem of the assurance of integrated reports stems from the heterogeneous nature of data included in these reports. Our findings related to the significant involvement of non-accountancy entities in the assurance processes supports the importance of multidisciplinary teams and the need for new professional competencies to be developed. Additionally, the large scale involvement of Big Four companies suggests that the assurance of integrated reports is not only difficult in terms of competencies, but also in terms of the necessary human and material resources.

A limitation of our research lies in the relatively small number of reports included in the sample. A solution might ne the analysis of the integrated reports included in the Global Reporting Initiative database.

A significant number of our results are different from the results of studies based on sustainability reports. For this reason, we believe that the assurance of integrated reports should be treated by specialized researchers as a stand-alone research area.

Traditional auditing practices and professional competencies are regularly reoriented to suit the audit objectives in new domains; however, where these practices and competencies seem deficient, the audit objectives may be redefined to align them with existing audit and assurance-focused competencies. Emerging audit and assurance technologies are ultimately formalized in order to present them as objective and, rational, thereby contributing to their wider acceptance. 


\section{REFERENCES}

1. Deloitte (2014), CFOs and Sustainability: Shaping their roles in evolving environment, Available at: http://www2.deloitte.com/content/dam/Deloitte/global/ Documents/Risk/dttl-risk-Deloitte-CFOs_and_ Sustainability-2014.pdf [Accessed 20 August, 2015].

2. Eccles, R.G., Krzus, M.P. and Watson, L.A. (2012), Integrated Reporting Requires Integrated Assurance. In Effective Auditing for Corporates: Key Developments in Practice and Procedures, edited by Joe Oringel, 161-178. London: Bloomsbury Information Ltd.

3. Huggins, A., Green, W.J. and Simnett, R. (2011), Engagements on greenhouse gas statements: is there a role for assurers from the accounting profession?, Current Issues in accounting, vol. 5, no. 2, A1 - A12.

4. IAASB (2015a), Exploring assurance on integrated reporting and other emerging developments in external reporting, Available at:

https://www. ffac.org/publications-resources/exploringassurance-integrated-reporting-and-other-emergingdevelopments_[Accessed 20 August, 2015].

5. IAASB (2015b): Agenda Item 13, Integrated Reporting - Discussion, Available at: http://www.ifac. org/system/files/meetings/files/20150615-iaasbagenda_item_13-integrated_reporting_cover-final.pdf [Accessed 20 August, 2015].

6. IAASB (2015c), Agenda Item E, Innovation Working Group (WG) - Report Back, Available at: http://www.ifac.org/system/files/meetings/files/201503 09-Agenda_Item_E-Innovation_WG_Report_Back_ Issues-final.pdf [Accessed 20 August, 2015].

7. IAASB (2015d): Agenda Item E.2, Assurance on Integrated Reports: An Emerging and Innovative Landscape, Available at: http://www.ifac.org/system/ files/meetings/files/20190309-IAASB-CAGAgenda_Item_E.2_IR_Awareness_Paper-final.pdf [Accessed 25 August, 2015].

8. IFAC (2008), Assurance Engagements Other Than Audits or Reviews of Historical Financial Information. International Standard on Assurance Engagements 3000. In IFAC Handbook, Available at: http://www.ffac.org/Members/DownLoads/2008_IAAS
B_Handbook_Part_I-Compilation.pdf [Accessed 20 August, 2015].

9. IIRC (2015), Assurance on $\langle\mathbb{R}\rangle$. Overview of feedback and call to action, July 2015, Available at, from: http://integratedreporting.org/wp-content/ uploads/2015/07/IIRC-Assurance-Overview-July2015.pdf [Accessed 6 August, 2015].

10. IIRC (2014), Assurance on $\langle\mid R\rangle$. An introduction to the discussion, Available at: http://integratedreporting. org/wp-content/uploads/2014/07/Assurance-on-IR-anintroduction-to-the-discussion.pdf [Accessed 6 August, 2015].

11. KPMG (2008), KPMG international survey of corporate sustainability reporting, Available at: http://www.kpmg.com/global/en/issuesandinsights/arti clespublications/pages/sustainability-corporateresponsibility-reporting-2008.aspx [Accessed 20 August, 2015].

12. KPMG (2013), The KPMG Survey of Corporate Responsibility Reporting 2013, Available at: http://www.kpmg.com/Global/en/lssuesAndlnsights/Ar ticlesPublications/corporate-responsibility/Documents/ corporate-responsibility-reporting-survey-2013.pdf [Accessed 20 August, 2015].

13. KPMG (2015), Currents of change. The KPMG survey of corporate responsibility reporting, Available at: http://www.kpmg.com/cn/en/ issuesandinsights/articlespublications/pages/kpmgsurvey-of-corporate-responsibility-reporting-2015-0201511.aspx [Accessed 4 January, 2016]

14. Lungu, C.I., Caraiani, C., Dascălu, C. and Sahlian, D.N. (2010), Concepts and policies of social and environmental standards and corporate reporting practice, Anale. Seria Ştiințe Economice. Timişoara (Annals. Economics Science Series. Timişoara), vol. XVI, pp. 614-622.

15. Oprişor, T. (2015), Contributions to an improved framework for integrated reporting, Accounting and Management Information Systems, vol. 14, no. 3, pp. 483-507.

16. Simnett, R., Vanstraelen, A. and Chua, W.F. (2009), Assurance on general purpose non-financial reports: An international comparison, Accounting Review, vol. 84, no. 3, pp. 937-967. 